\title{
Design and Simulation of Butterfly-Shaped Filtenna with Dual Band Notch for Portable UWB Applications
}

\author{
Fatimah K. Juma'a*, Falih M. Alnahwi \\ Electrical Engineering Department, College of Engineering, University of Basrah, Basrah, Iraq
}

\author{
Correspondence \\ * Fatimah Kamil Juma'a \\ Electrical Engineering Department, \\ University of Basrah, Basrah, Iraq. \\ Email: fatimahkamil5353@gmail.com
}

\begin{abstract}
A compact and low cost butterfly shaped UWB filtenna with a pair of parasitic elements and a pair of slits is proposed in this work. The filtenna is supposed to be designed on a common and low-cost FR4 substrate with overall dimensions of $26 \mathrm{~mm} * 20 \mathrm{~mm} * 1.6 \mathrm{~mm}$.By inserting a pair of $\lambda_{g} / 2$ ( where $\lambda_{g}$ is waveguide wavelength) D-shaped parasitic elements around the antenna feed line, the radiation of the $5 \mathrm{GHz}$ WLAN applications is canceled to eliminated the interference . Furthermore, the rejection of the $X$-band satellite downlink is achieved by engraving a pair of $\lambda_{g} / 4 \mathrm{~J}$-shaped slits on the ground plane. The simulation results exhibits the perfect coverage of the proposed filtenna for the UWB frequency band as well as the elimination of the undesired radiation within the filtenna operating band.
\end{abstract}

KEYWORDS: Antenna, Band-notch, Filtenna , (UWB) Filtenna.

\section{INTRODUCTION}

Nowadays, Ultra-wideband (UWB) systems have gained much attraction due to its special properties like low cost, simplicity, and reduced spectral power density. In response to its wide coverage of frequencies, they become a vital candidate for indoor high speed wireless communications systems. UWB systems have drawn the attention of both academic and industrial environments since the Federal Communications Commission (FCC) specified the 3.1 to $10.6 \mathrm{GHz}$ unlicensed band for them [1], which overlaps with a number of other critical wireless services such as WLAN $(5.15-5.825 \mathrm{GHz})$ and X-band satellite $(7.3-8.7 \mathrm{GHz})$. The interference with these important radiations causes a signal distortion and loss of sensitivity [2]. Hence, filtering is necessary for better utilization for the UWB communications. This filtering mechanism can be presented by modifying the UWB antenna patch in such a way that some band notches appears within the antenna frequency coverage. Unfortunately, engraving slots at the antenna patch results in noticeably distorted radiation pattern [3]. Therefore, the solution of the band notch filtering can be achieved by combining a band notch filter with the UWB antenna to form a special filtering antenna called band notch filtenna.

Some issues may flourish due to the combination of (antenna + filter) such as the structure size, complex matching network, and high insertion loss [4-7]. Consequently, researchers have been motivated to integrate the band notch filter within the UWB antenna feed line [8]. Many methods were proposed to generate band notches such as but not limited to stubs [9], rings [ 10], and slots [11-13]. For miniaturization purposes, the filtenna radiators are attached by some parasitic elements and some slots and slits were added to reduce the first resonant frequency of the designed filtenna, which results in significant size reduction [14-15].

In this paper, a compact and low cost butterfly shaped UWB filtenna with dual band notches by inserting a pair of parasitic elements and a pair of slits is proposed. The radiation around WLAN frequency $(5 \mathrm{GHz})$ is canceled by inserting a pair of $\lambda_{g} / 2 \mathrm{D}$-shaped parasitic elements around the antenna feed line. On the other hand, the elimination of the X-band satellite downlink is accomplished by etching a pair of $\lambda_{g} / 4 \mathrm{~J}$-shaped slits on the ground plane. The overall antenna size of the proposed filtenna is convenient for UWB application, and the simulation results reveal the a very good coverage for the UWB frequency band. In addition, the results show an acceptable elimination of the unwanted radiation.

\section{FiLTENNA DESIGN}

This section describes the antenna geometry and the design process of the final structure. The design goals are concluded by: achieving impedance bandwidth covering the wide frequency range of the UWB applications with reasonable gain value, providing stable radiation pattern 
across the whole desired band, rejecting the undesired band (the band-notch) that obtained by two different types of resonators.

The proposed filtenna structure is illustrated in Fig. 1. The filtenna consists of a butterfly shaped patch which acts as a UWB monopole antenna with a D-shaped parasitic resonator around the feed line and $\mathrm{J}$-shaped slits at the ground plane. The butterfly patch is proposed to obtain a UWB matching characteristics with as small antenna size as possible. The defected ground structure also plays an important role in providing wide impedance bandwidth. The antenna is printed on an FR4 substrate with (permittivity of $\left(\varepsilon_{r}\right) 4.3$, a loss tangent 0.025 and thickness $(h)$ of $1.6 \mathrm{~mm}$ ). The antenna is fed by $50 \mathrm{ohm}$ microstrip feed line with a width of $W_{f}$ and length of $L_{f}$ to couple the input signal with the radiating patch. The analysis of the proposed antenna dimensions can be determined from [16]:

$$
\begin{gathered}
\mathrm{W}_{\mathrm{p}}=\frac{\mathrm{c}}{2 \mathrm{f}_{\mathrm{r}}} \sqrt{\frac{2}{\varepsilon_{\mathrm{r}}+1}} \\
\mathrm{~L}_{\mathrm{p}}=\frac{\mathrm{c}}{2 \mathrm{f}_{\mathrm{r}} \sqrt{\varepsilon_{\mathrm{reff}}}}-2 \Delta \mathrm{L}
\end{gathered}
$$

Where $\mathrm{W}_{\mathrm{p}}$ is the patch width, $f_{r}$ is the first resonant frequency of the antenna, $\mathrm{L}_{\mathrm{p}}$ is the patch length, $\varepsilon_{\text {reff }}$ is the effective dielectric constant, and $\Delta L$ is introduced by the fringing effects. In other words, $\Delta L$ is the extended incremental distance of each open end of the patch, which can be approximated by [16]:

$$
\begin{aligned}
& \varepsilon_{\mathrm{reff}}=\frac{\varepsilon_{\mathrm{r}}+1}{2}+\frac{\varepsilon_{\mathrm{r}-1}}{2}\left[1+12 \frac{\mathrm{h}}{\mathrm{W}_{\mathrm{p}}}\right]^{-1 / 2} \\
& \frac{\Delta L}{h} \approx 0.412 \frac{\left(\varepsilon_{r e f f}-0.3\right)\left[\frac{W p}{h}+0.264\right]}{\left(\varepsilon_{\text {reff }}-0.258\right)\left[\frac{W p}{h}+0.8\right]}
\end{aligned}
$$

where $h$ is the height of substrate. In the microstrip feed line, the characteristic impedance of the microstrip line is given by[16]:

$$
Z_{c}=\frac{120 \pi}{\sqrt{\varepsilon_{\text {reff }}}} * \frac{1}{\frac{W_{f}}{h}+1.393+0.667 \ln \left(\frac{W_{f}}{h}+1.444\right)}
$$

Optimized design parameters of proposed filtenna are given in Table I.

\section{Parametric Study}

In the previous section, it is noticed that several parameters impact the resonant frequencies and the matching characteristics of the filtenna system. In this section, the effect of each of these parameters will be demonstrated. It is worth to mention that the simulation results are acquired with the aid of CST Microwave Studio simulation suite [17].

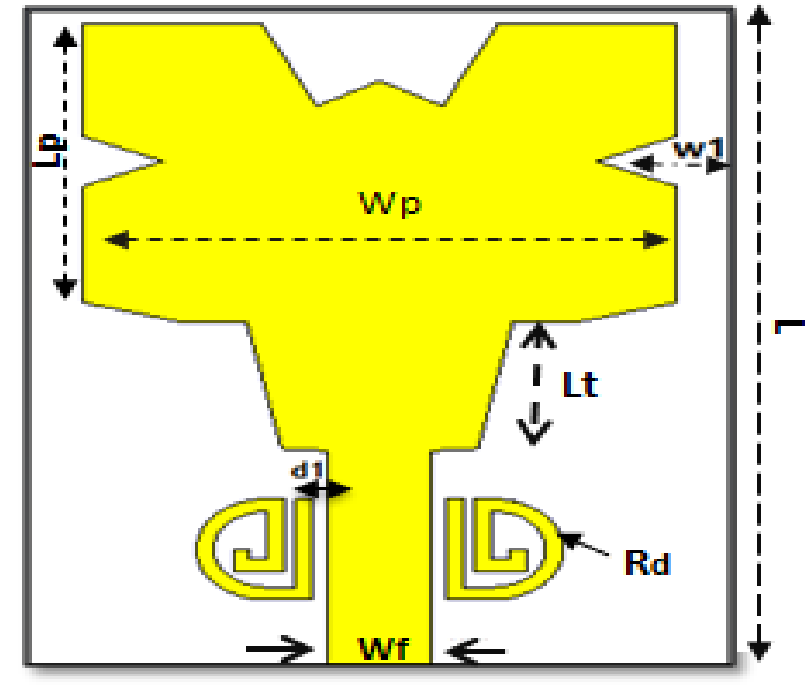

(a)

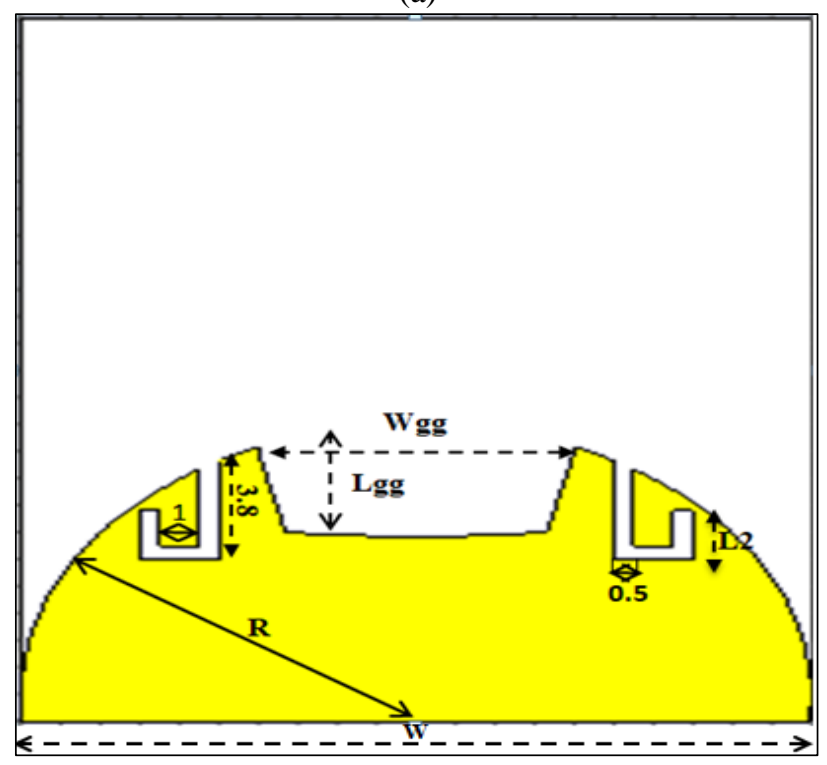

(b)

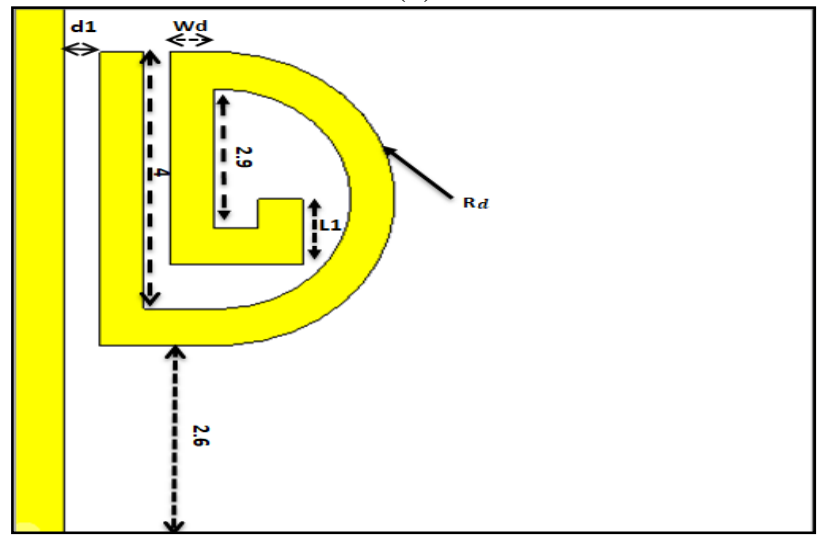

(c)

Fig. 1: Geometry of the proposed filtenna. (a) Top view (b) Back view (c) The D-shaped parasitic element. 


\section{A. Analysis of Butterfly Shaped Reference Antenna:}

The results of varying the fundamental design parameters $\left(W_{1}, L_{g g}\right.$, and $\left.L_{t}\right)$ on the antenna reflection coefficient are shown in Figs. 2 (a) through 2 (c) . Fig 2(a) illustrates the impact of varying the value of $W_{1}$ on the antenna operation frequency. It has a significant effect on the second resonant frequency $(7.3 \mathrm{GHz})$ with very little impress on the first resonant frequency $(3.6 \mathrm{GHz})$ since it does not affects the overall size of the antenna patch. The value of $W_{1}=6.2 \mathrm{~mm}$ provides the widest bandwidth because it results in a reduced value for the reflection coefficient. Furthermore, it is observed from Figures.2(b) and (c) that the impedance-matching characteristics of the antenna at the higher resonant frequencies are highly dependent on values of $L_{g g}$ and $L_{t} . L_{g g}=3.1 \mathrm{~mm}$, and $L_{t}=5 . \mathrm{mm}$ are very consistence values to set the antenna reflection coefficient below $-10 \mathrm{~dB}$ along the frequency range $(3-11.6 \mathrm{GHz})$ which perfectly covers the UWB specified band $(3.1-10.6 \mathrm{GHz})$.

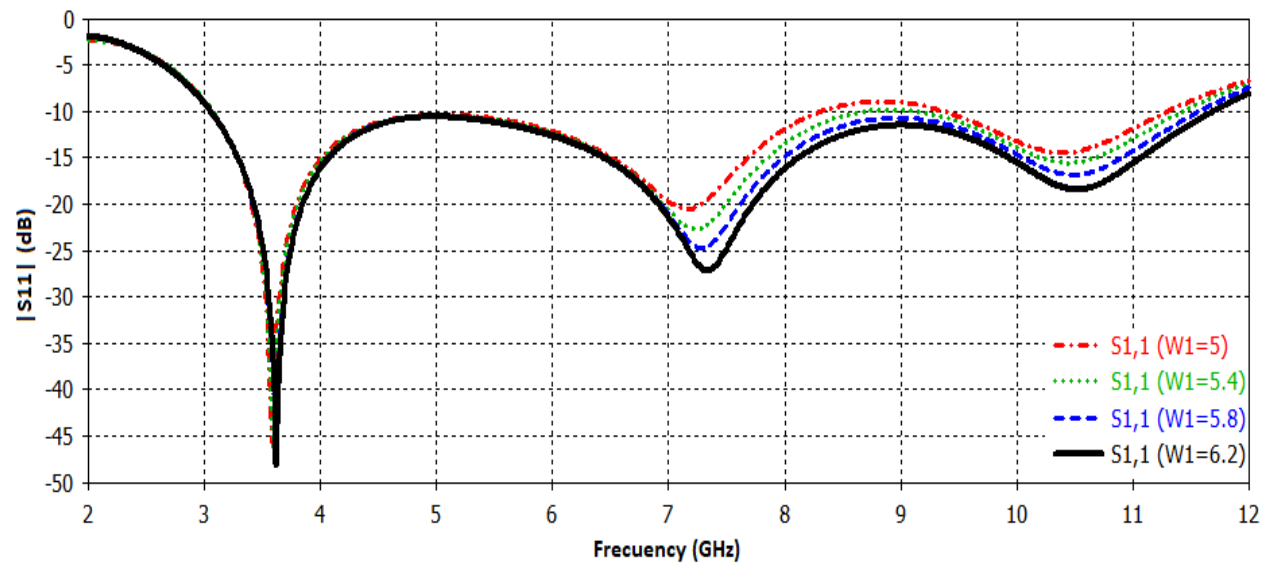

(a)

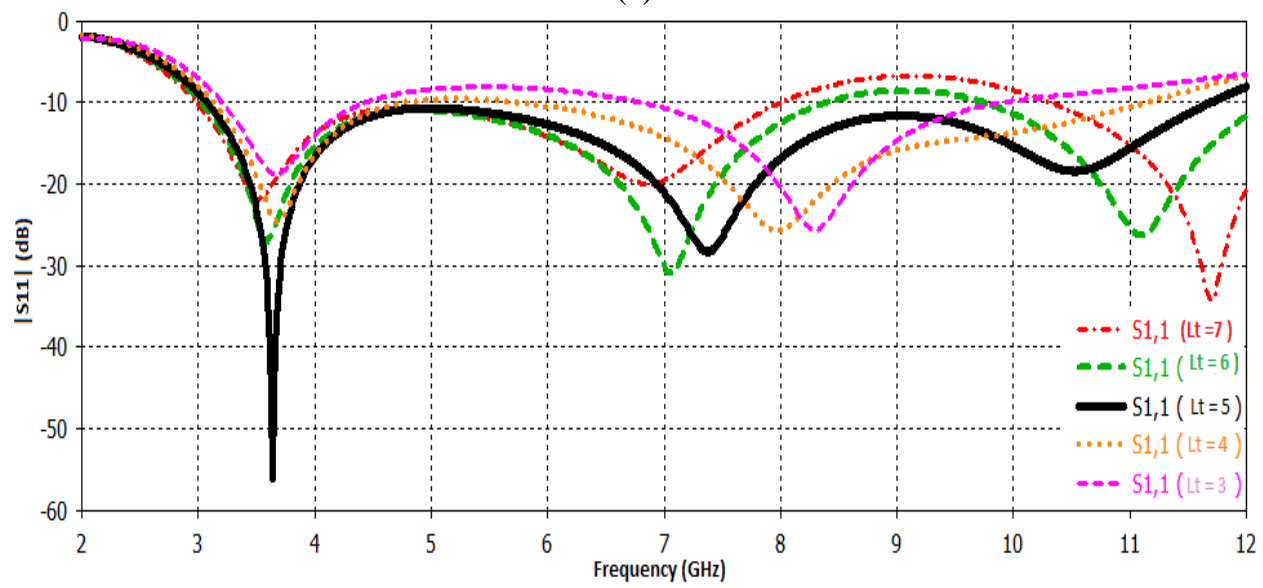

(b)

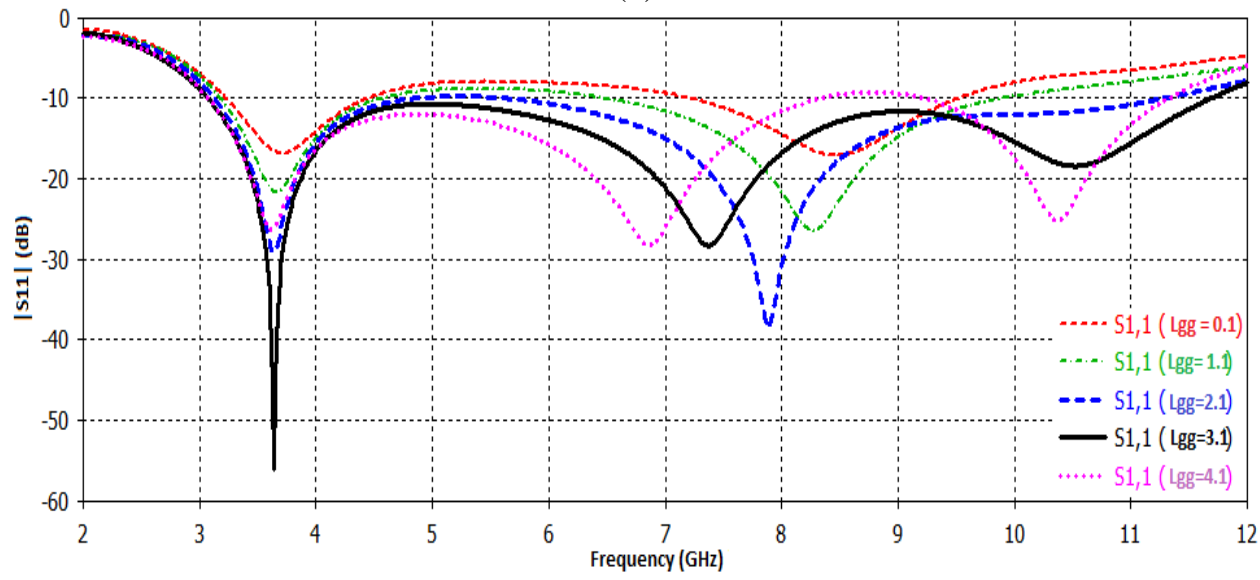

(c)

Fig. 2 : Antenna reflection coefficient for the butterfly shaped antenna without band notch at (a) $L_{g g}=3.1 \mathrm{~mm}, \mathrm{~L}_{\mathrm{t}}=5 \mathrm{~mm}$, and different values of $W_{1}$, (b ) $W_{1}=6.2 \mathrm{~mm}, \mathrm{~L}_{\mathrm{t}}=5 \mathrm{~mm}$, and different values of $L_{g g}$, and (c ) $L_{g g}=3.1 \mathrm{~mm}, W_{1}=6.2 \mathrm{~mm}$, and different values of $\mathrm{L}_{\mathrm{t}}$. 


\section{B. Analysis of Proposed Filtenna:}

In order to realize high selectivity and desired rejection bandwidth, two D-shaped parasitic elements are developed beside the transmission line. The electrical length of these parasitic elements is $\lambda_{g} / 2$, which can be estimated from the center frequency of the band notch by using the following formula:

$$
\mathrm{l}=\frac{\lambda_{g}}{2}=\frac{\mathrm{c}}{2 \mathrm{f}_{r} \sqrt{\varepsilon_{\mathrm{reff}}}}
$$

where $\lambda_{g}$ is the guided wavelength. The notched frequency can be tuned by changing the length of parasitic element to improve the performance. Fig. 3 (a) exhibits the Voltage Standing Wave Ratio (VSWR) of the proposed filtenna after changing the D-shaped parasitic element length. $L_{1}=0.9 \mathrm{~mm}$ is corresponding to the perfect cancelation for the $5 \mathrm{GHz}$ WLAN applications because the center frequency of the band notch is fixed at $5.5 \mathrm{GHz}$. Therefore, the overall length of the D-shaped element is equal to ( $16.75 \mathrm{~mm}$ ).

Two J-shaped slits with electrical length equal to $\lambda_{g} / 4$ are introduced in the microstrip ground plane to offer a remarkable influence on the rejected-band. The band-rejected impedance bandwidth and the center frequency are controlled by the length of this proposed element. Fig 3 (b) depicts the effect of the slit length on the VSWR of the proposed filtenna. $L_{2}=1.6 \mathrm{~mm}$ represents the suitable value that cancels the radiation of the downlink $\mathrm{X}$-band satellite communications. Consequently the overall length of the $\mathrm{J}$-shaped slit is equal to $(6.4 \mathrm{~mm}$ ). In addition, it worth mentioning that when the dimensions of J-shaped slits are changed, the corresponding band notch of each one would be changed individually.

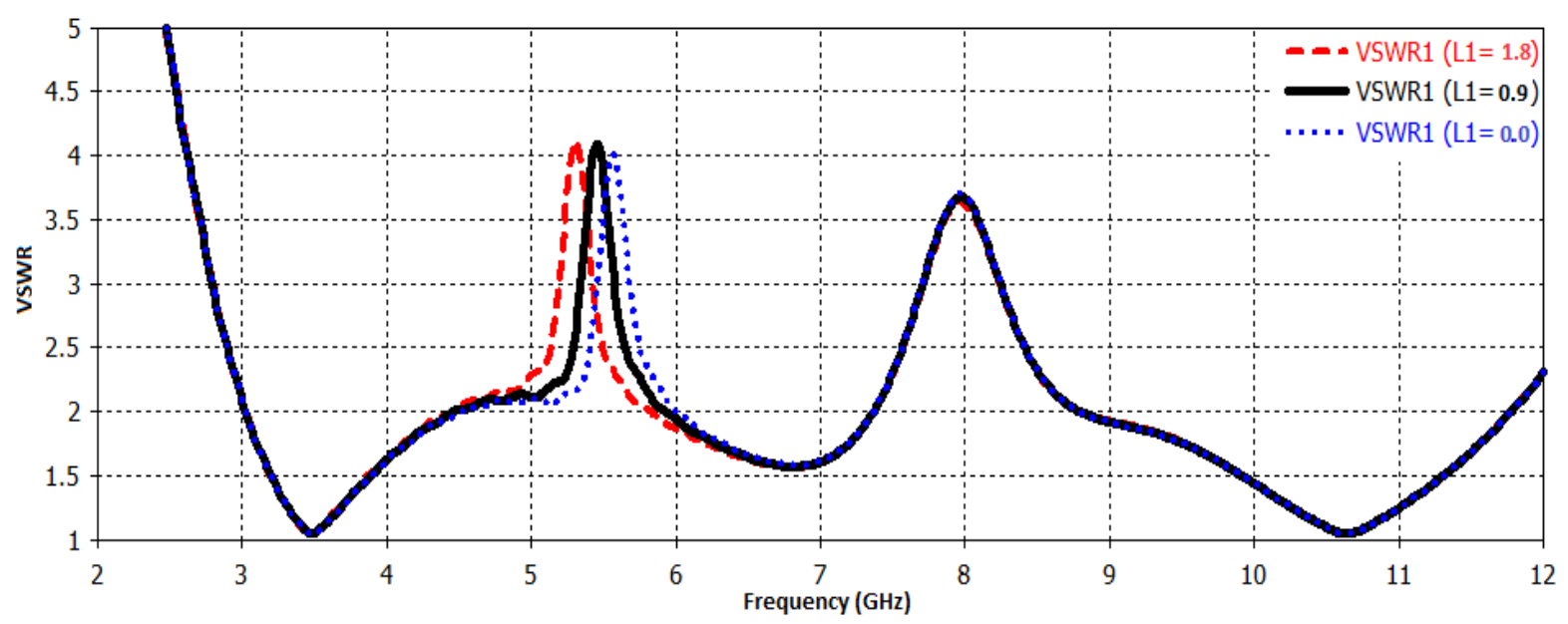

(a)

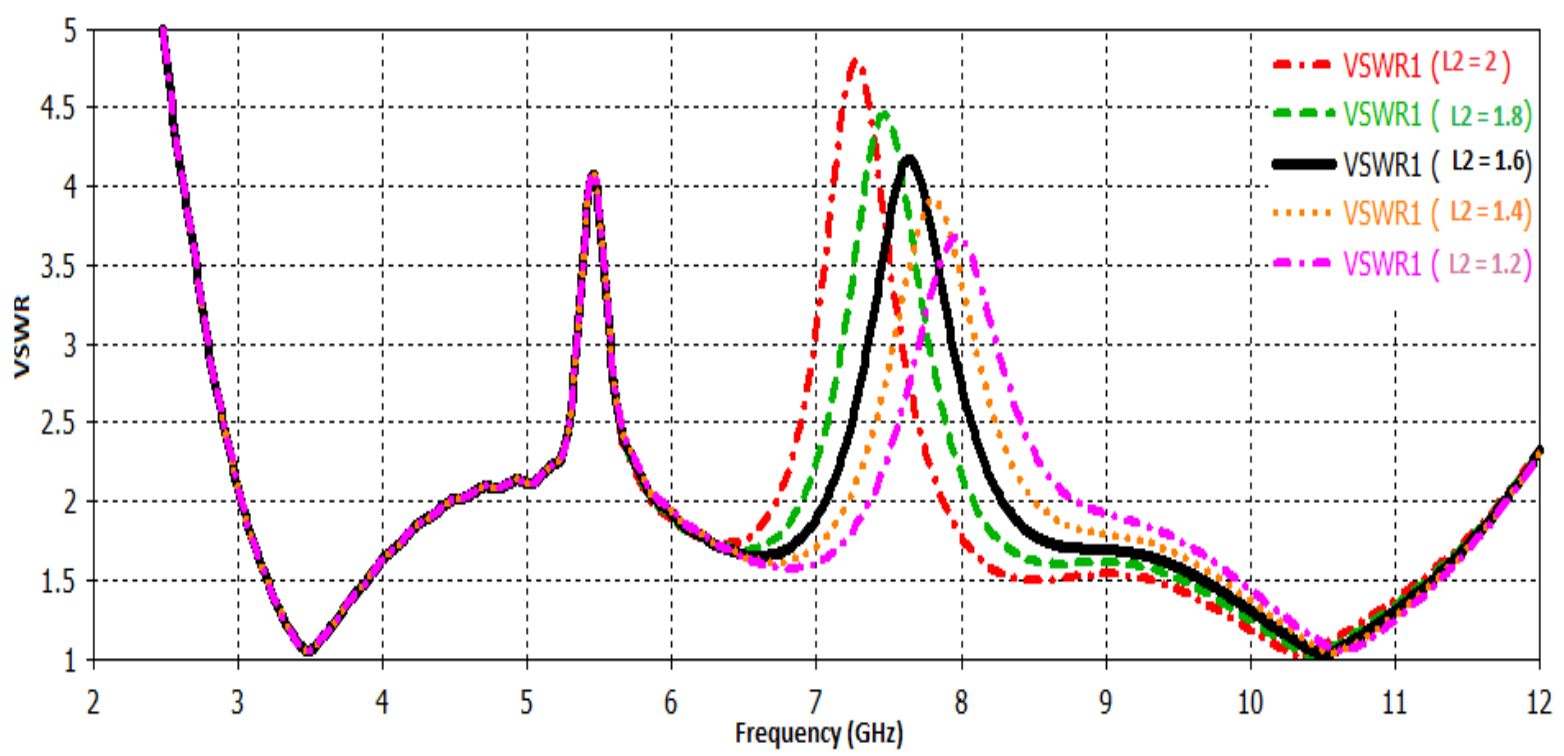

(b)

Fig.3: Simulated VSWR of the butterfly shaped filtenna after varying the length of (a) the D-shaped parasitic element and (b) the J-shaped slit. 
TABLE I

Optimized Design PARAMETERS Of THE PRESENTED FILTENNA

\begin{tabular}{|c|c|c|c|}
\hline Parameter & $\begin{array}{c}\text { Dimension } \\
(\mathrm{mm})\end{array}$ & Parameter & $\begin{array}{c}\text { Dimension } \\
(\mathrm{mm})\end{array}$ \\
\hline$W$ & 20 & $W_{1}$ & 6.2 \\
\hline$L$ & 26 & $L_{t}$ & 5 \\
\hline$W_{f}$ & 3 & $L_{1}$ & 0.9 \\
\hline$L_{f}$ & 8.6 & $R$ & 10 \\
\hline$W_{p}$ & 17 & $R_{d}$ & 2 \\
\hline$L_{p}$ & 11.1 & $W_{d}$ & 0.5 \\
\hline$L_{g g}$ & 3.1 & $d_{1}$ & 0.4 \\
\hline$W_{g g}$ & 8 & $L_{2}$ & 1.6 \\
\hline
\end{tabular}

\section{SIMULATION RESULTS}

The simulated reflection coefficient (S11) as a function of frequency of the butterfly shaped filtenna with and without the band rejection filter are shown in Fig. 4. Assuming -10 $\mathrm{dB}$ level as a reference, the reflection coefficient bandwidth of the UWB antenna without the filter has a bandwidth extended from $3.0 \mathrm{GHz}$ to $11.6 \mathrm{GHz}$. However, after attaching the band notch generation elements, dual band notch starts to show up. As a result, the filtenna effectively suppresses WLAN (5.15-5.825 GHz) and X-band down link satellite communications $(7.3-8.7 \mathrm{GHz})$.

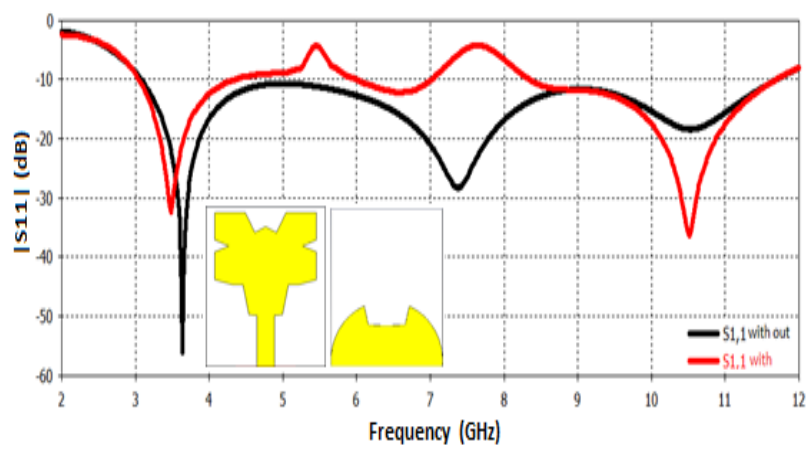

Fig .4: simulated reflection coefficient of the proposed filtenna with and without filter.

For supplementary explanation of the proposed filtenna mechanism, Fig. 5 shows the simulated current distribution at the center frequency of each notched band. It is clearly seen that the current is concentrated around the band notch elements. This means that the current is concentrated around the band rejection elements to form an energy storage characteristics rather than forming a radiated energy that reaches the antenna terminals.

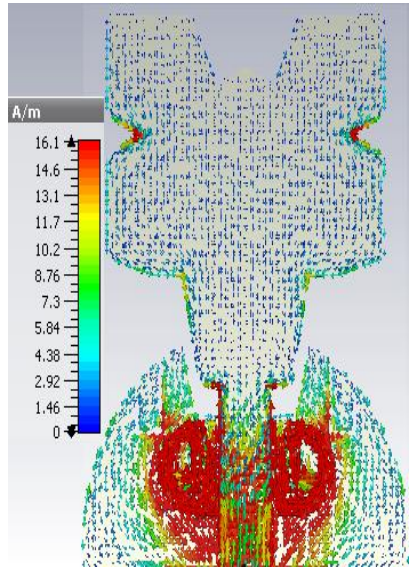

(a)

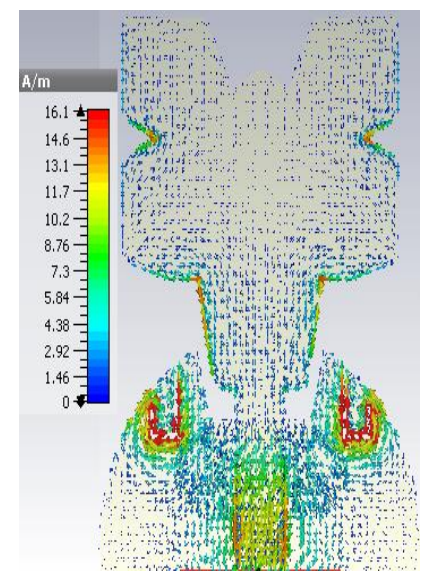

(b)
Fig.5: Simulation of current distribution at (a) $5.5 \mathrm{GHz}$ (b) $7.5 \mathrm{GHz}$.

The simulated gain distributions as a function of frequency with and without the band notches are shown in Figs. 6(a) and (b) respectively. As expected, the gain is stable in the operating band in case of the antenna without band notch. However, it undergoes a sharp reduction in the notched frequency band, and this verifies the good performance of the proposed band rejection elements.

The simulated power pattern of the antenna at the H-plane and E-plane at $3.6 \mathrm{GHz}, 7.3 \mathrm{GHz}$, and $10.5 \mathrm{GHz}$ are illustrated in Figs.7(a), (b), and (c) respectively. The antenna provides omnidirectional radiation patterns in the $\mathrm{H}$-plane at whole frequency band, while a bidirectional power pattern shape in the E-plane [18]. It is important to notice that the antenna has almost a stable power pattern for the entire frequency band. Moreover, the filtenna power pattern is very suitable for portable UWB gadgets since its omnidirectional characteristics make it independent of the device position.

\section{ConClusions}

A compact and low cost butterfly shaped UWB filtenna with a pair of parasitic elements and a pair of slits has successfully been proposed to present UWB frequency coverage with dual band notches. The reflection coefficient bandwidth of the UWB antenna without the filter has a bandwidth extended from 3.0 GHz to $11.6 \mathrm{GHz}$. However, after attaching the band notch generation elements, two band notch starts to show up. Consequently, the filtenna significantly suppresses the WLAN $(5.15-5.825 \mathrm{GHz})$ and $\mathrm{X}$-band down link satellite communications (7.3-8.7 GHz). The simulation results also highlight the reasonable antenna gain with reduced values at the notched bands. Furthermore, the power pattern of the filtenna system is omnidirectional along the entire operating band, which is suitable for UWB portable devices. 


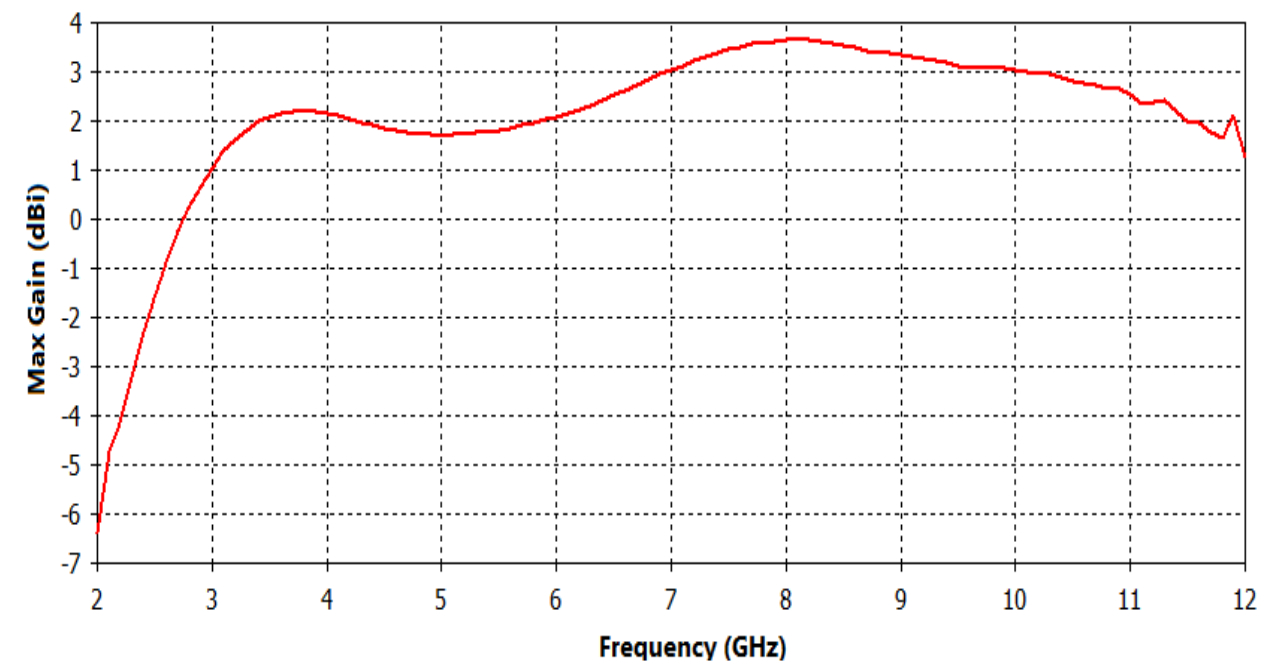

(a)

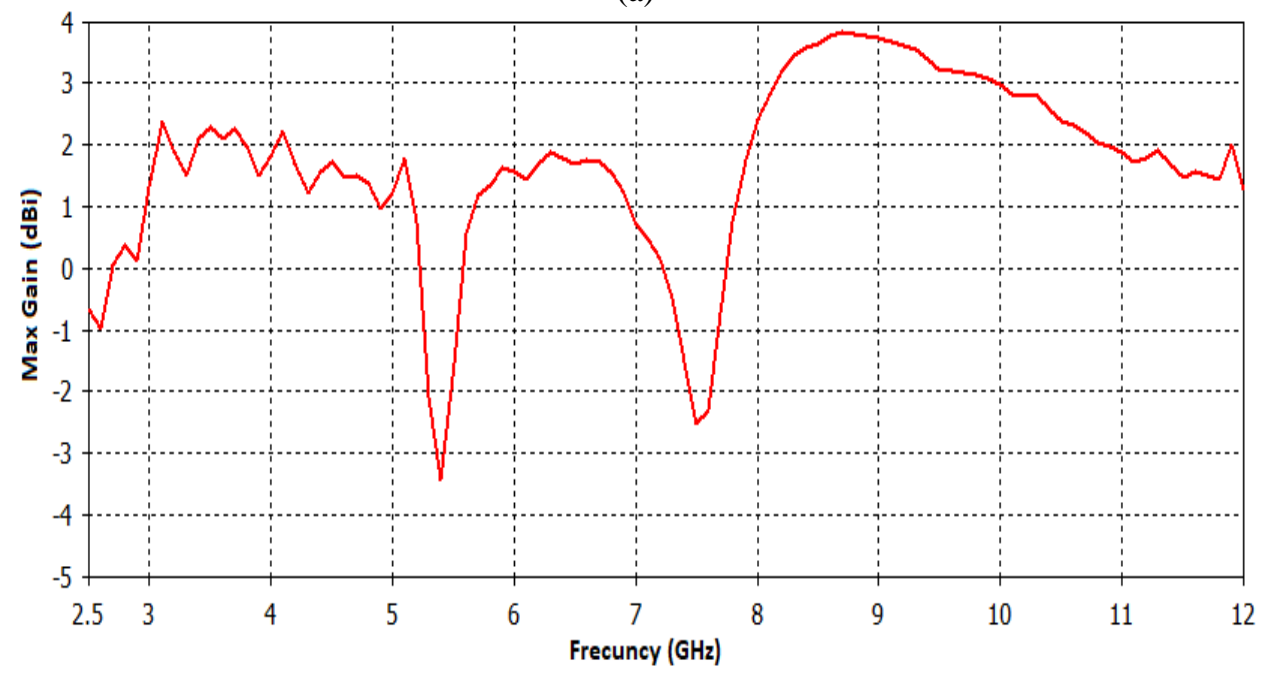

(b)

Fig.6 simulation gains of the proposed filtenna (a) without filter and (b) with filter.
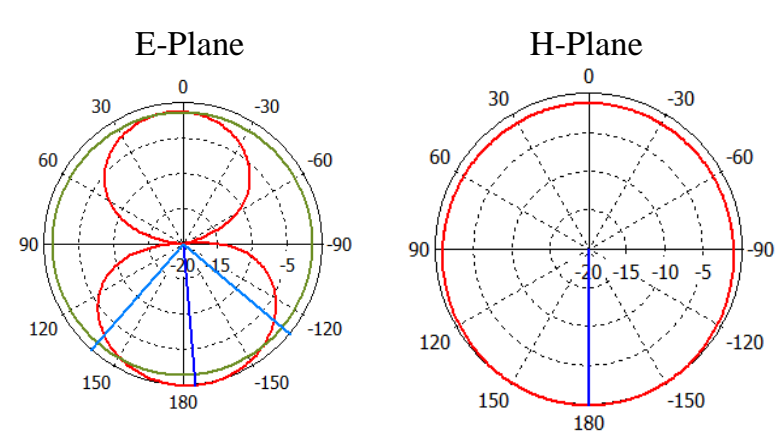

(a)
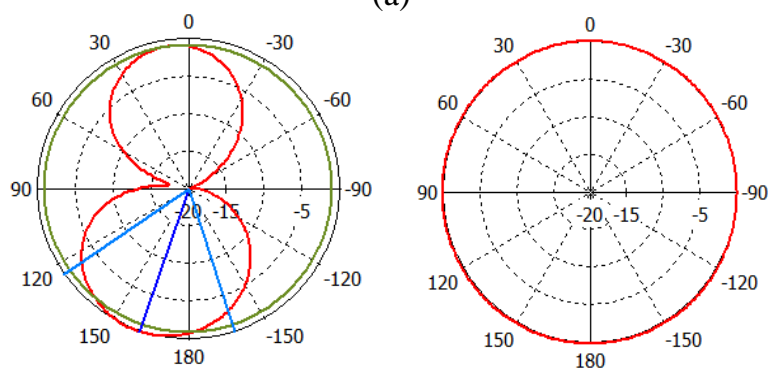
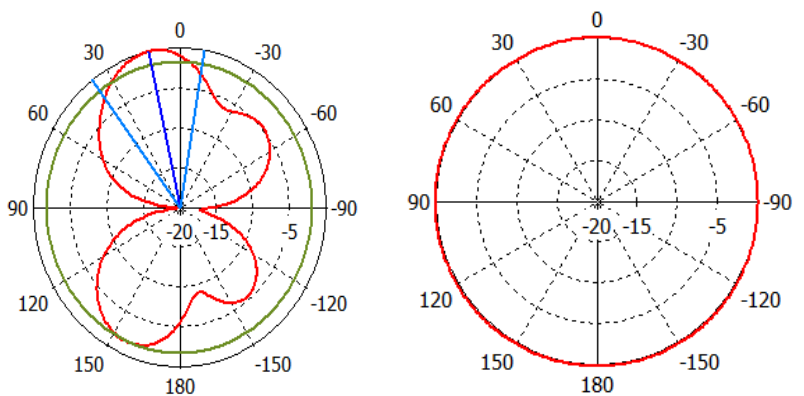

(c)

Fig.7: Simulation Radiation patterns of the proposed butterfly shaped filtenna at the frequencies (a)3.6 $\mathrm{GHz},(\mathrm{b}) 7.3 \mathrm{GHz},(\mathrm{c}) 10.5 \mathrm{GHz}$.

\section{CONFLICT OF INTEREST}

The authors have no conflict of relevant interest to this article.

(b) 


\section{REFERENCES}

[1] ] Federal Communications Commission, "Revision of Part 15 of the Commission's Rules Regarding Ultra Wideband Transmission System," First Rep. Order, FCC 2, vol. 48, 2002.

[2] W. Ahmad, and D. Budimir, " Reconfigurable UWB Filtennas with Sharp WLAN Dual Band notch," European Microwave Integrated Circuits conference, pp. 377-380, 7-8 Sept 2015, Paris, France.

[3] J. Ghimire, and D. Choi, "Design of a Compact Ultra wideband U-Shaped Slot Etched on a Circular Patch Antenna with Notch Band Characteristics for Ultra wideband Applications," International Journal of Antennas and Propagation, pp.1-10, 18 February 2019.

[4] Y. Tawk, J. Costantine, and C. Christodoulou,“ Reconfigurable Filtennas and MIMO in Cognitive Radio Applications," IEEE Transactions on antenna and propagation, Vol. 62, No. 3,pp. 1074-1082, March 2014

[5] V. Rekha, P. Pardhasaradhi, B. Madhav, and Y. Devi , "Dual Band Notched Orthogonal 4-Element MIMO Antenna With Isolation for UWB Applications," IEEE Access, Vol. 8, pp. 145871-145880, 2020.

[6] Y. Tawk, J. Costantine, and C. Christodoulou , "A Varactor-Based Reconfigurable Filtenna," IEEE Antennas and Wireless propagation litters , Vol. 11,pp.716-719,2012.

[7] C. Yu, W. Hong, Z . Kuai, and H. Wang, "Ku-Band Linearly Polarized Omnidirectional Planar Filtenna," IEEE Antennas and Wireless propagation litters, Vol. 11,pp.310-313,2012.

[8] T. Kataria, M. Bastida, J. Reyes-Ayona, Jose. Cervantes, , and A. Corona-Chavez, "Planar Differential Filtenna for Communications," Electromagnetics Research Letters, Vol. 79,pp. 33-38, 2018.

[9] F. Zhu, S. Gao, et al, "Multiple Band-Notched UWB Antenna with Band-Rejected Elements Integrated in Feed Line," IEEE Trans. on Antennas and Prop., vol. 61, no. 8, pp. 3952-3960, August 2013.

[10] M. Rahman, A. Haider, and M. Naghshvarianjahromi, "A Systematic Methodology for the Time-Domain Ringing Reduction in UWB Band-Notched Antennas," IEEE Antennas and Wireless propagation litters, VOL. 19, NO. 3, pp. 482- 486, March 2020.

[11] W. Lui, C. Cheng, and H. Zhu, "Compact frequency notched UWB fractal printed slot antenna," IEEE Microwave and Wireless Components., vol. 16, no. 4, pp. 224-226, April 2006.

[12] S. Mehta , V. Tyagi , and H.Choudhary, "Design and Analysis of Switchable Filtenna with Triple Band Notch Characteristics," IEEE Trans ,Vol. 6,pp. 12727-12738, Issue 7, July 2017.

[13] F. Alnahwi, A. Abdalhameed, H. Swadi, A. Abdullah, "A compact wide-slot UWB antenna with reconfigurable and sharp dual-band notches for underlay cognitive radio applications," Turkish Journal of Electrical Engineering \& Computer Sciences, pp. 94-105, January 2019.

[14] J. Kim, C.S. Cho. And J. Lee, "5.2 GHz notched ultra wide-band antenna using slot-type SRR," Electron. Letter, vol.42, No.6, pp.315-316, March. 2006.
[15] W. S. Lee, D. Z. Kim, K. J. Kim, and J. W. Yu, "Wide-band planar monopole antennas with dual band-notched characteristics," IEEE Transactions on Microwave Theory \& Techniques, Vol. 54, No. 3, 28002806, 2008.

[16] C. A. Balanis, Antenna Theory: Analysis and Design, 3rd ed. New York, NY, USA: Wiley, 2005.

[17] "CST Microwave Studio User Manual," ver. 2010, CST GmbH, Darmstadt, Germany, 2010.

[18] N. Abdulhussein, and A. Abdullah, "Design of a Wide Dual-Band Coplanar Probe Feed Antenna for WLANs Applications," The 3rd Scientific Conference of Electrical and Electronic Engineering Researches (SCEEER), Basrah, Iraq, pp.13-16, 15-16 June 2020. DOI: $10.37917 /$ ijeee.sceeer.3rd.2 